An Introduction to System Programming - Based on the PDP11 


\section{Macmillan Computer Science Series}

\section{Consulting Editor}

Professor F. H. Sumner, University of Manchester

S.T. Allworth, Introduction to Read-time Software Design

Ian O. Angell, A Practical Introduction to Computer Graphics

G.M. Birtwistle, Discrete Event Modelling on Simula

T.B. Boffey, Graph Theory in Operations Research

Richard Bornat, Understanding and Writing Compilers

J.K. Buckle, The ICL 2900 Series

J.K. Buckle, Software Configuration Management

J.C. Cluley, Interfacing to Microprocessors

Robert Cole, Computer Communications

Derek Coleman, A Structured Programming Approach to Data*

Andrew J.T. Colin, Fundamentals of Computer Science

Andrew J.T. Colin, Programming and Problem-solving in Algol 68*

S.M. Deen, Fundamentals of Data Base Systems*

P.M. Dew and K.R. James, Introduction to Numerical Computation in Pascal

K.C.E. Gee, Introduction to Local Area Computer Networks

J.B. Gosling, Design of Arithmetic Units for Digital Computers

David Hopkin and Barbara Moss, Automata*

Roger Hutty, Fortran for Students

Roger Hutty, Z80 Assembly Language Programming for Students

Roland N. Ibbett, The Architecture of High Performance Computers

H. Kopetz, Software Reliability

E.V. Krishnamurthy, Introductory Theory of Computer Science

Graham Lee, From Hardware to Software: an introduction to computers

A.M. Lister, Fundamentals of Operating Systems, second edition*

G.P. McKeown and V.J. Rayward-Smith, Mathematics for Computing

Brian Meek, Fortran, $P L / 1$ and the Algols

Derrick Morris, An Introduction to System Programming - Based on the PDPII

Derrick Morris and Roland N. Ibbett, The MU5 Computer System

John Race, Case Studies in Systems Analysis

Colin J. Theaker and Graham R. Brookes, A Practical Course on Operating Systems

B.S. Walker, Understanding Microprocessors

Peter J.L. Wallis, Portable Programming

I.R. Wilson and A.M. Addyman, A Practical Introduction to Pascal-with BS 6192, second edition 


\title{
An Introduction to System Programming - Based on the PDP11
}

\author{
Derrick Morris \\ Department of Computer Science \\ University of Manchester
}

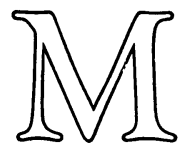

MACMILLAN PRESS

LONDON 
(C) Derrick Morris 1983

All rights reserved. No part of this

publication may be reproduced or transmitted, in any form or by any means, without permission.

Published by

THE MACMILLAN PRESS LTD

London and Basingstoke

Companies and representatives

throughout the world 


\section{Contents}

Preface

Acknowledgements

1. The Binary System 1

1. 1 Number Representation 1

1.2 Binary Arithmetic 2

1.3 Negative Number Representation 3

1.4 Notations for Binary Numbers 5

1.5 Radix Conversion 6

1. 6 Exercises 8

2. A Simple Computer - MUO 9

2. 1 The Memory 9

$\begin{array}{ll}2.2 \text { The Control Unit } & 10\end{array}$

2.3 Overall Operation 11

2. 4 The Instruction Format 11

$\begin{array}{ll}2.5 & \text { Operation of the Control Unit } \\ 2.6\end{array}$

2.6 Programming MUO 13

$\begin{array}{ll}2.7 \text { Exercises } & 21\end{array}$

3. The Structure of the PDPll 22

3. 1 Addressing Modes 25

3. 1.1 Addressing Modes 0, 2, 4 and $6 \quad 25$

3. 1.2 Examples of the use of modes 0,2, 4 and $6 \quad 27$

3. 1. 3 Addressing Modes 1, 3, 5 and 728

3. 1. 4 Examples of the use of modes 1, 3, 5 and $7 \quad 28$

3. 1. 5 Special Registers 29

3. 1.6 Address modes 2, 3, 6 and 7 with PC 30

3. 2 Computational Instructions 31

3.2. 1 Double Operand Instructions 31

3.2.2 Single Operand Instructions 32

3.2.3 Condition Codes 34

3.2. 4 Implicit Setting of Condition Codes 35

3.2.5 Expliclt Setting of Condition Codes 35

3. 3 Branch Instructions 35

3.3. 1 Examples Using Branch Instructions 37

3. 4 Subroutines 38

3.5 The Jump Instruction 40

3. 6 Byte Addressing 40

3.7 Anomalies in the PDPII Instruction Set 41

3. 8 Exercises 43 
4. Operation and Bootstrapping

4. 1 Manual Operation of the PDP11 45

4.2 Manual Operation of an LSIII 48

4. 3 An Octal Loader 50

4. 4 A Practical Approach to Bootstrapping 55

4. 5 Bootstrapping by 'Cross Compiling' 57

4.6 Automatic Bootstrapping $\quad 59$

4.7 Exercises $\quad 60$

5. A Simple Assembly Language 61

5. 1 A SAL Program 62

5.2 Constants 62

5.3 Instructions $\quad 65$

5.4 Operands 66

5.5 Constant Statements $\quad 66$

$\begin{array}{ll}5.6 & \text { Directive Statements } \\ 5.7 & 67\end{array}$

5.7 The Special Name 'Dot' 68

5. 8 Comment Statements $\quad 69$

5.9 Library Subroutines $\quad 69$

5. 10 Simple Input Output Subroutines $\quad 69$

5. 10.1 Octal Input 70

5. 10.2 Octal Output 71

5.11 An Example of a Complete SAL Program 71

5. 12 Exercises $\quad 73$

\begin{tabular}{ll} 
6. & Arithmetic Subroutines \\
\hline
\end{tabular}

6. 1 Multiplication $\quad 77$

$\begin{array}{ll}6.2 \text { Division } & 79\end{array}$

6. 3 Double Length Arithmetic 82

6.3. 1 Double Length Addition and Subtraction 82

6.3.2 Multiplication 83

6. 4 Floating Point Arithmetic $\quad 85$

6. 4. 7 Floating Point Addition $\quad 86$

6.4.2 Floating Point Subtraction 90

6. 4.3 Floating Point Multiply 90

6. 4. 4 Floating Point Division 93

6.4.5 Floating Point Rounding Errors 94

6. 5 Binary Coded Decimal Arithmetlc 95

6.5.1 16-Bit Unsigned Binary Coded Decimal Addition 96

6.5.2 32-Bit BCD Addition 98

6.5.3 BCD Subtraction. 99

6.5.4 BCD Multiplication and Division 100

6.5.5 Conversion from BCD to Binary 100

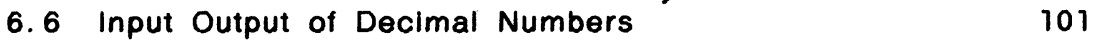

6.6.1 Decimal Input Subroutine 102

6.6.2 Decimal Output Subroutine 103

6.7 Exercises 105 
7. Implementation of the Assembler

7.1 The Data Structures of the Assembler 108

7. 1. 1 The Line Buffer 109

$\begin{array}{ll}7.1 .2 & \text { The Source Buffer } \\ 711\end{array}$

7.1.3 The Name List 111

7.1.4 The Character Table 116

7.1.5 The Function Table 117

7.1.6 Summary of the Lists Required 117

$\begin{array}{lll}7.2 & \text { The Subroutine Structure of the Assembler } & 118\end{array}$

7.3 The Coding of the Assembler 118

7.3. 1 Global variables $\quad 119$

$\begin{array}{ll}\text { 7.3.2 Subroutine specifications } & 120\end{array}$

$\begin{array}{ll}\text { 8. Control of Input and Output } & 123\end{array}$

8. 1 The Basic Mechanism for Input Output 124

8.2 Teletype Input Output 126

$\begin{array}{ll}\text { 8. } 3 \text { Bootstrap Sequences } & 127\end{array}$

$\begin{array}{ll}8.4 \text { Buffering } & 130\end{array}$

8.5 Interrupts 132

8.5. 1 Interrupt Entry 133

8.5.2 The Processor Status Register (PS) 134

8.6 Implementation of Input Buffering 135

8.7 Implementation of Output Buffering 139

$\begin{array}{ll}\text { 8. } 8 \text { Using 'Floppy' Discs } & 141\end{array}$

8.9 Exercises 144

Appendices

1 Summary of PDP11 Instruction Code 146

2 SAL Code for the MUO Interpreter 148

3 The Flowcharts and Code for SAL 151

4 The Octal Code for the SAL Assembler 179

5 Allocation of Device and Interrupt Addresses 183

6 7-Bit ASCII Character Code 184

Index 


\section{Preface}

This book is intended as the text for an introductory practical course in System Programming based on the PDP11. It contains a description of the machine. the techniques used in programming it in machine language, and the programs needed to convert a machine, totally without software. into a usable system at assembly language level. The material might be viewed as both a bridge between hardware and software courses and as a platform upon which courses concerned with the design of compilers and operating systems might be built.

The material given is lllustrated by reference to the PDPII and is intended to be used in an environment in which 'hands on' access can be provided. It has grown out of a first year course of about 40 lectures and 10 half day practical sessions given in the Computer Science Department of the University of Manchester over the past 10 years. Mostly the computers used have been the PDPII/20 and the PDP11/40, but this presentation is aimed more at the LSI11.

In fact. the course is now supported by means of a PDP $11 / 44$ to which sixteen PDT 11 with VT105 terminals are connected. The $11 / 44$ is controlled by a general purpose operating system. and it is primarily used for file management and program assembly. Students downline load their assembled programs into the single user PDT11's, where they have hands on access. The only system software necessarlly resident in the PDTIl's are the TRANSMIT sequence and OCTAL LOADER introduced in Chapter 4.

Exercises are given at the end of each chapter which are appropriate to the materlal it contains. Those in the first three chapters are paper exercises only. From Chapter 4 onwards some exercises require a computer. 


\section{Acknowledgements}

I am indebted to my colleagues and the many students who have helped to shape and assemble the material presented in this book. In particular. I am enormously indebted to Dr. P. C. Capon whose advice and assistance has been invaluable, and without whose encouragement I would have given up long ago. Also my sincere thanks go to Pat Cook who has tirelessly struggled through the almost endless series of iterations to which this text has been subjected, to produce the final camera copy on a rather inadequate text formatting system. 